\title{
Breast fibroblasts in both cancer and normal tissues induce phenotypic transformation of breast cancer stem cells: a preliminary study
}

\author{
Bixiao Wang ${ }^{1}$, Chunfang Xi ${ }^{1,2}$, Mingwei Liu ${ }^{3}$, Haichen Sun ${ }^{4}$, Shuang Liu ${ }^{4}$, Lei Song ${ }^{3}$, Hua Kang ${ }^{\text {Corresp. } 1}$ \\ 1 Department of General Surgery, Xuanwu Hospital, Capital Medical University, Beijing, China \\ 2 Department of Breast Surgery, Shanxi Provincial People's Hospital, Taiyuan, Shanxi, China \\ 3 State Key Laboratory of Proteomics, National Center for Protein Sciences, Beijing Proteome Research Center, Beijing, China \\ 4 Surgery Lab, Xuanwu Hospital, Capital Medical University, Beijing, China \\ Corresponding Author: Hua Kang \\ Email address: kanghuamd@163.com
}

Background. Breast cancer stem cells (BCSCs) are associated with the invasion of breast cancer. In recent years, studies have demonstrated different phenotypes among BCSCs. Furthermore, BCSCs of diverse phenotypes are present at different tumour sites and different histological stages. Fibroblasts are involved in the phenotypic transformation of BCSCs. Cancer-associated fibroblasts (CAFs) participate in the induction of epithelialmesenchymal transition, thereby promoting the acquisition of stem cell characteristics, but little is known about the role of normal fibroblasts (NFs) in the phenotypic transformation of BCSCs or about the effect of CAFs and NFs on BCSC phenotypes. Methods. Six pairs of primary CAFs and NFs were isolated from surgical samples of breast cancer patients and subjected to morphological, immunohistochemical, cell invasion and proteomics analyses. After establishing a cell culture system with conditioned medium from CAFs and NFs, we used the mammosphere formation assay to explore the effect of CAFs and NFs on the selfrenewal ability of BCSCs. The effect of CAFs and NFs on the phenotypic differentiation of BCSCs was further analysed by flow cytometry and immunofluorescence. Results. The isolated CAFs and NFs did not show significant differences in cell morphology or $\alpha$-SMA expression, but cell invasion and proteomics analyses demonstrated heterogeneity among these fibroblasts. Both CAFs and NFs could promote the generation of BCSCs, but CAFs displayed a greater ability than NFs in promoting mammosphere formation. Conditioned medium from CAFs increased the proportion of $A L D H 1^{+} B C S C s$, but conditioned medium from NFs was more likely to promote the generation of $\mathrm{CD} 44^{+} \mathrm{CD} 24^{-}$BCSCs from MCF-7 cells. Discussion. This study validated the heterogeneity among CAFs and NFs and expanded on the conclusion that fibroblasts promote the generation of cancer stem cells. Our results particularly emphasized the effect of NFs on the phenotypic transformation of BCSCs. In addition, this study further highlighted the roles of CAFs and NFs in the induction 
of different phenotypes in BCSCs. 


\section{Manuscript Title}

2 Bixiao Wang ${ }^{1}$, Chunfang $\mathrm{Xi}^{1,2}$, Mingwei $\mathrm{Liu}^{3}$, Haichen $\mathrm{Sun}^{4}$, Shuang $\mathrm{Liu}^{4}$, Lei Song ${ }^{3}$, Hua Kang ${ }^{1 \#}$

$3 \quad{ }^{1}$ Department of General Surgery, Xuanwu Hospital, Capital Medical University, Beijing, China

$4 \quad{ }^{2}$ Department of Breast Surgery, Shanxi Provincial People's Hospital, Taiyuan, Shanxi, China

$5{ }^{3}$ State Key Laboratory of Proteomics, National Center for Protein Sciences, Beijing Proteome Research Center, 6 Beijing, China

$7 \quad{ }^{4}$ Surgery Lab, Xuanwu Hospital, Capital Medical University, Beijing, China

8 Corresponding Author:

9 Hua Kang ${ }^{1 \#}$

10 No. 45 Changchun Street, Xicheng District, Beijing, 100053, PR of China

11 Email address: kanghua@xwh.ccmu.edu.cn 


\section{Breast fibroblasts in both cancer and normal tissues induce} phenotypic transformation of breast cancer stem cells: a preliminary study

Bixiao Wang ${ }^{1}$, Chunfang $\mathrm{Xi}^{1,2}$, Mingwei $\mathrm{Liu}^{3}$, Haichen $\mathrm{Sun}^{4}$, Shuang $\mathrm{Liu}^{4}$, Lei Song ${ }^{3}$, and Hua Kang ${ }^{1}$

1. Department of General Surgery, Xuanwu Hospital, Capital Medical University, Beijing, China

2. Department of Breast Surgery, Shanxi Provincial People's Hospital, Taiyuan, Shanxi, China

3. State Key Laboratory of Proteomics, National Center for Protein Sciences, Beijing Proteome Research Center, Beijing, China

4. Surgery Lab, Xuanwu Hospital, Capital Medical University, Beijing, China

\section{Abstract}

Background. Breast cancer stem cells (BCSCs) are associated with the invasion of breast cancer. In recent years, studies have demonstrated different phenotypes among BCSCs. Furthermore, BCSCs of diverse phenotypes are present at different tumour sites and different histological stages. Fibroblasts are involved in the phenotypic transformation of BCSCs. Cancer-associated fibroblasts (CAFs) participate in the induction of epithelial-mesenchymal transition, thereby promoting the acquisition of stem cell characteristics, but little is known about the role of normal fibroblasts (NFs) in the phenotypic transformation of BCSCs or about the effect of CAFs and NFs on BCSC phenotypes.

Methods. Six pairs of primary CAFs and NFs were isolated from surgical samples of breast cancer patients and subjected to morphological, immunohistochemical, cell invasion and proteomics analyses. After establishing a cell culture system with conditioned medium from CAFs and NFs, we used the mammosphere formation assay to explore the effect of CAFs and NFs on the selfrenewal ability of BCSCs. The effect of CAFs and NFs on the phenotypic differentiation of BCSCs was further analysed by flow cytometry and immunofluorescence.

Results. The isolated CAFs and NFs did not show significant differences in cell morphology or $\alpha-$ SMA expression, but cell invasion and proteomics analyses demonstrated heterogeneity among these fibroblasts. Both CAFs and NFs could promote the generation of BCSCs, but CAFs displayed a greater capacity for promoting mammosphere formation than NFs. Conditioned 
41 medium from CAFs increased the proportion of $\mathrm{ALDH} 1^{+} \mathrm{BCSCs}$, but conditioned medium from

42 NFs was more likely to promote the generation of $\mathrm{CD} 44^{+} \mathrm{CD} 24^{-} \mathrm{BCSC}$ from $\mathrm{MCF}-7$ cells.

43 Discussion. This study validated the heterogeneity among CAFs and NFs and expanded on the conclusion that fibroblasts promote the generation of cancer stem cells. Our results particularly emphasized the effect of NFs on the phenotypic transformation of BCSCs. In addition, this study further highlighted the roles of CAFs and NFs in the induction of different phenotypes in BCSCs.

\section{Introduction}

Cancer stem cells are a subpopulation of cancer cells that are characterized by self-renewal and multidirectional differentiation capabilities. Since breast cancer stem cells (BCSCs) were isolated in 2003 and shown to exhibit strong tumourigenicity (Al-Hajj et al. 2003), a large number of studies have described the use of CD44, CD24 and aldehyde dehydrogenase-1 (ALDH1) for the identification of BCSCs (Chiotaki et al. 2016; Yang et al. 2017). These studies have shown that $\mathrm{BCSCs}$ are associated with tumour progression such as recurrence, metastasis and treatment resistance, and consequently contributed to the poor outcome of breast cancer. However, not all BCSC markers are expressed in all breast cancer subtypes, and these markers may be limited to particular subtypes or associated with invasive subtypes of breast cancer (Boesch et al. 2016). For example, $\mathrm{CD} 44^{+} \mathrm{CD} 24-\mathrm{BCSC}$ are abundant in triple-negative breast cancer (TNBC) (Bernardi et al. 2012), and ALDH $1^{+}$BCSCs are associated with the BRCA1 mutational status (Somasundaram et al. 2016). In addition, these cell populations are enriched in primary tumour lesions after radiotherapy and chemotherapy but are seldom associated with either disease-free or overall survival (Li et al. 2008). However, ALDH1 ${ }^{+}$BCSCs are associated with HER-2 overexpression and loss of expression of oestrogen receptors and progesterone receptors (Ginestier et al. 2007), and the presence of this population may be used as an independent predictor of breast cancer prognosis (Mansour \& Atwa 2015). These findings indicate that BCSCs may vary by cancer subtype. Even for a particular breast cancer lesion, there may be differences in stem cell phenotypes at different tumour sites and different histological stages (A \& Lopes 2017). Therefore, we hypothesize that a process of transformation is involved in the variation of BCSC phenotypes.

The tumour matrix or the tumour microenvironment can affect the biological behaviour of cancer cells and plays an important role in the disease progression (Bussard et al. 2016). Fibroblasts are the major cellular components in the tumour microenvironment, and fibroblasts that are activated by cancer cells are called cancer-associated fibroblasts (CAFs). Many studies have shown that 
74 CAFs play an important role in tumour formation, development, invasion, metastasis and resistance to treatment by secreting exosomes or a variety of cytokines and factors that remodel the extracellular matrix (Buchsbaum \& Oh 2016; Erdogan \& Webb 2017). CAFs are thus involved in inducing epithelial-mesenchymal transition and can promote the acquisition of stemness in breast cancer cells (Giannoni et al. 2010; Plaks et al. 2015). However, during the initial stages of formation of primary or metastatic lesions, the tumour microenvironment mostly contains normal fibroblasts (NFs). Some of these resting NFs can be activated due to inflammation, tissue damage, chronic fibrosis and other processes to become normal activated fibroblasts (NAFs) (Darby et al. 2016). However, very little is known regarding the function of the two populations of fibroblasts, $\mathrm{CAFs}$ and NAFs, during tumour formation and progression, especially regarding their effects on BCSCs.

As a preliminary investigation, we aimed to determine the roles of CAFs and NFs during the acquisition of BCSC phenotypes and to explore the similarities and differences between BCSCs that are induced by CAFs and NFs from a functional and observational perspective to lay the foundation for further mechanistic exploration.

\section{Materials and methods}

1. Cells and cell culture

\subsection{CAFs and NFs}

For the primary culture of CAFs and NFs, tissues were collected from 6 breast cancer patients who underwent complete surgical resection of their tumours at Xuanwu Hospital, Capital Medical University. This study was approved by the appropriate Institutional Review Board and Human Ethics Committee, and all participants were adequately informed before the use of their samples. The donors' clinical information is summarized in Table 1.

Table 1 Clinical information of the specimen donors. Age represents the age of the donor at the time of surgery. The histological type of the tissue was invasive ductal carcinoma (IDC). Oestrogen and progesterone receptor status is indicated as "positive/negative" with the corresponding percentage of positive cells. HER-2 positivity in the tissues was determined by fluorescence in situ hybridization (FISH). 
Paired fibroblasts were isolated from the same patient from corresponding tumour and healthy breast tissues more than $3 \mathrm{~cm}$ away from carcinoma. After being harvested, tissues were stored in Dulbecco's modified Eagle's medium (DMEM) (Gibco) supplemented with 1\% penicillinstreptomycin (Gibco) and immediately transported on ice to the laboratory. The tissues were mechanically chopped, washed three times with phosphate-buffered saline (PBS) (Gibco) and enzymatically digested with prepared reagents for $9-15 \mathrm{~h}$ at $37^{\circ} \mathrm{C}$. The reagent mixture used for digesting NFs contained collagenase type I (Sigma) and hyaluronidase (Sigma), whereas that for digesting CAFs contained only collagenase. After the cell suspension was filtered with 100-mesh screens and centrifuged at $1000 \mathrm{rpm}$ for $4 \mathrm{~min}$, the cell pellet was resuspended in the fresh DMEM containing $10 \%$ heat-inactivated foetal bovine serum (FBS) (BI). These cells were cultured at $37^{\circ} \mathrm{C}$ in $5 \% \mathrm{CO}_{2}$ and $95 \%$ air, and half of the medium was replaced three times a week. All CAFs and NFs were used in the experiments within 8 passages.

\subsection{Cell lines}

The human breast cancer cell line MCF-7 was purchased from Cobioer Biosciences Corporation (Nanjing, China) and cultured in DMEM containing $10 \% \mathrm{FBS}$ at $37^{\circ} \mathrm{C}$ in a humidified atmosphere of $5 \% \mathrm{CO}_{2}$ and $95 \%$ air.

\subsection{Mammosphere culture and dissociation}

In a published report (Shaw et al. 2012), MCF-7 cells had the highest mammosphere-forming efficiency (MFE) among all kinds of breast cancer cell lines. Thus, we used the mammosphereforming capacity of cell lines derived from MCF-7 cells to purify and collect BCSCs. MCF-7 cells were cultured to 70-80\% confluency and suspended in DMEM/F12 (Gibco) containing 2\% B27 (Gibco), $20 \mathrm{ng} / \mathrm{mL}$ epidermal growth factor (EGF) (Gibco) and $20 \mathrm{ng} / \mathrm{ml}$ recombinant basic fibroblast growth factor (bFGF) (PeproTech) to form single cell suspensions. The cell suspensions were plated at a density of $2.5 \times 10^{5}$ cells $/ 10-\mathrm{cm}$ diameter dish with $10 \mathrm{ml}$ culture medium. The cells were incubated in a humidified atmosphere at $37^{\circ} \mathrm{C}$ and $5 \% \mathrm{CO}_{2}$ for 7 days without moving or disturbing the plates and without replenishing the medium. After a week, "primary mammospheres" were obtained, which were then collected by gentle centrifugation (580 g, $4 \mathrm{~min}$ ) and trypsinized with $0.05 \%$ trypsin $/ 0.53 \mathrm{mM}$ EDTA-4Na (Gibco). To ensure single cell suspension, the cells were passed three times through a $25 \mathrm{G}$ needle on a syringe and inspected under a microscope. The "secondary mammospheres" were plated at the same seeding density and incubated under the same conditions that were used for the generation of primary mammospheres. 
2. Immunocytochemistry

140

CAFs and NFs were cultured on coverslips at 50-60\% confluency. Then, the fibroblasts were fixed in cold acetone for $7 \mathrm{~min}$ and incubated overnight with a primary antibody against $\alpha$-SMA (1:100) (Abcam) at $4^{\circ} \mathrm{C}$ in a moist chamber. PBS was used as a control. After being washed three times with PBS, all coverslips were incubated with a peroxidase-conjugated secondary antibody for 15 min at room temperature, followed by incubation with 3,3'-diaminobenzidine (DAB). The coverslips with cells were then counterstained with haematoxylin for $2 \mathrm{~min}$ and placed on slides.

\section{Immunohistochemical staining}

Samples collected from the patients described above were fixed in formalin and embedded in paraffin. Then, the samples were cut into 4- $\mu \mathrm{m}$ sections with a microtome. All sections were airdried overnight, dewaxed in xylene and dehydrated in alcohol before staining. The primary antibody against $\alpha$-SMA was the same as that described above. Staining was performed according to the manufacturer's instructions. Antigen retrieval was performed by pressure cooking the sections for 1 min in EDTA.

\section{Preparation of conditioned medium}

CAFs and NFs were cultured to $70-80 \%$ confluency and were then washed with PBS. After that, cells were cultured in DMEM/F12 or DMEM with neither FBS nor other growth factors for $24 \mathrm{~h}$. The two types of media were pipetted into a centrifuge tube and centrifuged at 1,000 rpm for 5 min, and the supernatant was collected and stored at $-20^{\circ} \mathrm{C}$ in small aliquots to avoid repeated freeze-thaw cycles. Before use, 10\% FBS was added to the DMEM supernatant to form CM for the MCF7 cell invasion assay. Similarly, EGF, bFGF and B27 were added to the DMEM/F12 supernatant to form $\mathrm{CM}$ for BCSC-related experiments.

\section{Cell invasion assay}

Invasion assays were conducted using 8- $\mu \mathrm{m}$-pore Transwell inserts in 24-well plates (Corning). We added $25 \mu \mathrm{l}$ of growth factor-reduced phenol red-free Matrigel (BD), which was diluted in a 1:4 ratio with DMEM, to Transwell inserts on ice and incubated the inserts at $37^{\circ} \mathrm{C}$ without disturbance. After $2 \mathrm{~h}, 3 \times 10^{4} \mathrm{MCF}-7$ cells in $100 \mu \mathrm{FBS}$-free DMEM were seeded in the upper chamber. The plates were divided into the following three groups: a group with CM-derived from 
170 CAFs with 10\% FBS (CM-CAFs), a group with CM-derived from NFs with 10\% FBS (CM-NFs) 171 and a control group with DMEM and 10\% FBS. After $48 \mathrm{~h}$ of incubation at $37^{\circ} \mathrm{C}$ and $5 \% \mathrm{CO}_{2}$, the 172 cells remaining in the upper chambers were removed with a cotton swab, and the inserts were fixed 173 in cold $4 \%$ formaldehyde for $5 \mathrm{~min}$ and stained with $5 \%$ crystal violet for $5 \mathrm{~min}$. Then, the cells 174 that had invaded to the lower surface of the membranes were counted from 6 random fields of views with an inverted microscope at $400 \times$ magnification. The assay was performed in triplicate.

176

177

178

6. Protein analysis

\subsection{Sample preparation}

Proteins in culture supernatants were purified using an acetone precipitation method. For wholecell extractions, cell pellets were lysed with urea-containing lysis buffer $(8 \mathrm{M}$ urea and $100 \mathrm{mM}$ Tris-HCl pH 8.0). Protease inhibitors (Pierce ${ }^{\mathrm{TM}}$, Thermo Fisher Scientific) were added to protect proteins from degradation, and protein concentrations were measured using the Bradford assay (Eppendorf BioSpectrometer).

\subsection{Trypsin digestion of proteins}

For whole-cell proteome analyses, proteins were digested using the filter assisted sample preparation (FASP) method as follows: the protein samples were incubated with $1 \mathrm{M}$ dithiothreitol (DTT) at a final concentration of $5 \mathrm{mM}$ for $30 \mathrm{~min}$ at $56^{\circ} \mathrm{C}$; then, iodoacetamide (IAA) was added to the samples at a final concentration of $20 \mathrm{mM}$ and incubated in the dark at room temperature. After incubation for half an hour, the samples were mixed with DTT at a final concentration of 5 $\mathrm{mM}$ and kept in the dark for another $15 \mathrm{~min}$. Then, the protein samples were loaded onto $10-\mathrm{kD}$ Microcon filtration devices (Millipore) and centrifuged at 12,000 g for $20 \mathrm{~min}$ and washed twice with urea-containing lysis buffer $(8 \mathrm{M}$ urea and $100 \mathrm{mM}$ Tris- $\mathrm{HCl} \mathrm{pH} \mathrm{8.0)}$ and twice with $50 \mathrm{mM}$ $\mathrm{NH}_{4} \mathrm{HCO}_{3}$. Then, the samples were digested using trypsin at an enzyme to protein mass ratio of 1:25 overnight at $37^{\circ} \mathrm{C}$. Peptides were then extracted and dried (SpeedVac, Eppendorf).

\subsection{Mass spectrometric analysis and data processing}

Orbitrap Fusion liquid chromatography and tandem mass spectrometry (LC-MS/MS) analyses were performed on an Easy-n LC 1000 liquid chromatography system (Thermo Fisher Scientific) coupled to an Orbitrap Fusion MS and a nano-electrospray ion source (Thermo Fisher Scientific). Samples were dissolved in loading buffer ( $5 \%$ methanol and $0.1 \%$ formic acid) and loaded onto a 
202

203

204

205

206

207

208

209

210

211

212

217

218

219

220

221

222

223

224

225

226

227

228

229

230

231

232

233

234

$360-\mu \mathrm{m}$ ID x $2 \mathrm{~cm} \mathrm{C18} \mathrm{trap} \mathrm{column} \mathrm{at} \mathrm{a} \mathrm{maximum} \mathrm{pressure} 280$ bar with $12 \mu 1$ solvent A $(0.1 \%$

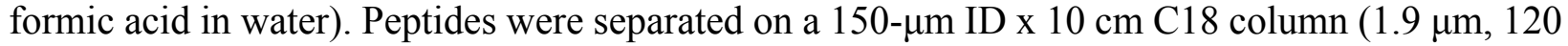
$\AA$, Dr Maisch $\mathrm{GmbH}$ ) with a series of adjusted linear gradients according to the hydrophobicity of fractions with a flow rate of $500 \mathrm{nl} / \mathrm{min}$. MS analysis was performed in a data-dependent manner with full scans (m/z 300-1,400) acquired using an Orbitrap Mass Analyser at a mass resolution of 120,000 at an $\mathrm{m} / \mathrm{z}$ of 200 . The top data-dependent speed mode was selected for fragmentation in the human collecting duct (HCD) cell at normalized collision energy of $32 \%$, and then fragment ions were transferred into the ion trap analyser with an automatic gain control (AGC) target of 5 $\times 10^{3}$ counts and maximum injection time of $35 \mathrm{~ms}$. The dynamic exclusion of previously acquired precursor ions was enabled at $18 \mathrm{~s}$.

Raw data were analysed in the Firmiana data analysis environment for protein identification and label-free quantification using a target-decoy approach to identify peptides and proteins at an FDR $<1 \%$ against the human protein RefSeq database (released 2013.07.01). Acetylation (protein N terminus) and oxidation (methionine), carbamidomethylation (cysteine) were set as variable modifications.

\section{Sphere formation assay}

Fourth and higher generation mammospheres were used for the experiments. Cell suspensions prepared as described above in CM and plated at a density of $500 \mathrm{cells} / \mathrm{cm}^{2}$ in ultra-low attachment 6-well plates ( $2 \mathrm{ml}$ of mammosphere medium per well). The plates were divided into 3 groups based on the medium used, namely, CM-CAFs, CM-NFs and DMEM/F12-control medium. All DMEM/F12-control medium used in mammosphere experiments contains DMEM/F12, EGF, bFGF and B27. After 6 days, we counted the number of mammospheres that were more than 50 $\mu \mathrm{m}$ in diameter and calculated MFE based on the following formula: MFE (\%) $=$ (number of mammospheres per well/number of cells seeded per well $) \times 100$. The assay was performed in triplicate.

\section{Flow cytometry}

CD24, CD44 and ALDH1 expression was analysed in cells harvested from fourth and higher generation mammospheres dissociated after 6 days of culture in CM. After preparing single cell suspensions in PBS, $1 \times 10^{6}$ cells were counted and resuspended in staining buffer and incubated for 30 min with anti-CD44 and anti-CD24 antibodies (BD) at the manufacturer's suggested dilutions at $4{ }^{\circ} \mathrm{C}$ in the dark. The labelled cells were washed and resuspended in PBS on ice. 
235 Additionally, $1 \times 10^{5}$ cells from the samples were subjected to the ALDEFLUOR assay 236 (Millipore). All samples were analysed with a flow cytometer (BD). Cells incubated with isotype 237 control antibodies corresponding to each fluorescent probe were used as negative controls. In 238 addition, cells incubated with diethylaminobenzaldehyde (DEAB), an inhibitor of ALDH1, were

239

240

241

242

243

244

245

246

247

248

249

250

251

252

253

254

255

256

257

258

259

260

261

262

263

264

265

266 used as negative controls for the ALDEFLUOR assay. The assay was performed in triplicate.

\section{Immunofluorescence staining}

For immunofluorescence, mammospheres were cultured on coverslips in CM for 6 days, fixed in cold acetone for $7 \mathrm{~min}$ and then stored in PBS. After being washed, the mammospheres were blocked in methanol containing hydrogen peroxide for $10 \mathrm{~min}$. Then, the mammospheres were incubated with primary antibodies (ALDH1A1, Proteintech) (CD44, Cell Signaling) at $4^{\circ} \mathrm{C}$ overnight in a humid chamber. After being washed 3 times with PBS, the cells were incubated for $1 \mathrm{~h}$ with secondary antibodies. The coverslips were mounted with mounting medium containing DAPI. Fluorescence signals were observed and images were obtained with a fluorescence microscope. The assay was performed in triplicate.

\section{Statistical analysis}

Data were presented as the means $\pm \mathrm{SD}$ for at least three independent experiments for every group. Statistical analyses were performed with SPSS 16.0 software. Statistical differences were analysed using two-tailed Student's t tests. Differences were considered significant at $\mathrm{P}$ values less than 0.05 .

Results

CAFs and their paired NFs were successfully isolated from six primary breast cancer samples and paired normal breast tissue specimens, respectively. The primary fibroblasts were successfully cultured in DMEM containing 10\% FBS, and these fibroblasts could grow well for at least 9 passages. Both CAFs and their paired NFs had similar spindle-like morphology (Fig. 1A-B). Depending on the age of the patients from whom the samples were obtained, senescent cells were observed in different passages, especially after the sixth passage. The cultured CAFs/NFs and breast cancer/adjacent normal tissues all expressed $\alpha$-SMA, which is considered myofibroblastspecific marker (Fig. 1C-1F). Then, a culture system with CM was established to identify the different roles of CAFs and NFs in the tumour's paracrine microenvironment. In contrast with the 
267

268

269

270

271

272

273

274

275

276

277

278

279

280

281

282

283

284

285

286

287

288

289

290

291

292

293

294

295

296

297

298

cells grown in culture systems with CM-NFs and DMEM with 10\%FBS, MCF-7 cells grown in culture systems with CM-CAFs displayed increased invasion (Fig. 1G-I). Therefore, CAFs and NFs could be isolated from different tissues and exerted different functions in the tumour microenvironment.

Figure 1. Cell morphology and a-SMA expression cannot be used to distinguish CAFs and NFs, but these fibroblasts differ in their biological functions. (A-B) CAFs and NFs are both morphologically characterized as large spindle-shaped cells with indented nuclei. Bar: $100 \mu \mathrm{m}$. (C-D) Immunohistochemical staining for $\alpha$-SMA in CAFs and NFs. Both samples are positive for $\alpha$-SMA expression. Bar: $100 \mu \mathrm{m}$. (E-F) Immunohistochemical staining for $\alpha$-SMA in a cancer tissue and a paracancerous tissue more than $3 \mathrm{~cm}$ away from a carcinoma. Bar: $100 \mu \mathrm{m}$. (G-I) Invasion of MCF-7 cells was affected by CM. Bar: $100 \mu \mathrm{m}$.

We collected samples of whole-cell extracts from 6 paired primary fibroblast lines cultured at 90$100 \%$ confluence. Label-free LC-MS/MS quantification was used to characterize the differences in protein expression between CAFs and NFs. In total, 7208 proteins were identified. With the criteria of up-regulation in at least 4 paired experiments and a fold-change $>2,200$ proteins were up-regulated in CAFs, and 5037 proteins were up-regulated in NFs. Quantitative data for the proteins up-regulated in CAFs is represented in the form of a heat map (Fig. 2A). The functions, biological processes (Fig. 2B) and Kyoto Encyclopaedia of Genes and Genomes (KEGG) pathways (Fig. 2C) associated with these proteins were also analysed. The proteomic data illustrated differences in protein expression between paired CAFs and NFs.

Figure 2 CAFs and NFs are heterogeneous in terms of their protein expression profiles, cellular functions and related signalling pathways. (A) Heterogeneity in the expression of selected proteins (fold-change $<-2$ or $>2, \mathrm{P}<0.05$ ) between CAFs and NFs. Blue represents down-regulated expression, and red indicates up-regulated expression. All data are transformed by $\log 2$ operation. (B) Gene ontology (GO)-based enrichment analysis of up-regulated proteins in CAFs (orange bars) and in paired NFs (blue bars), including cell component (CC), biological process (BP) and molecular function (MF). (C) KEGG pathway analysis for identifying major biological pathways that were different between CAFs (orange bars) and NFs (blue bars). 
To explore the role of CAFs and NFs in BCSCs, we employed a culture system with CM from corresponding fibroblasts and analysed the effect of the $\mathrm{CM}$ on mammosphere formation by MCF7 cells. Single cell suspensions of MCF-7 cells were cultured independently in CM-CAFs, CMNFs and DMEM/F12-control medium as mentioned above, without disturbing the plates. Mammospheres, with rounded shape and smooth boundaries, were observed by microscopy after 6 days of culture (Fig. 3A). Mammospheres greater than $50 \mu \mathrm{m}$ in diameter were counted and included in statistical analyses. The average size of the mammospheres was not noticeably different among the groups. However, the number of mammospheres formed in the groups with CM-CAFs and CM-NFs was approximately 3.84-fold and 2.85-fold higher, respectively, than that in the control group (Fig. 3B). Cells cultured in CM-CAFs had a greater MFE than the cells cultured in $\mathrm{CM}-\mathrm{NFs}(\mathrm{P}<0.05)$ (Fig. $3 \mathrm{C})$. Thus, $\mathrm{CM}-\mathrm{CAFs}$ demonstrated greater capability of inducing mammosphere formation than did CM-NFs.

Figure 3. Mammosphere formation by MCF-7 cells cultured in CM. (A) Mammosphere formation in MCF-7 cells in the control, CM-NFs (cultured in CM-NFs) and CM-CAFs (cultured in CM-CAFs) groups. Bar: $100 \mu \mathrm{m}$. (B) Number of mammospheres greater than $50 \mu \mathrm{m}$ in diameter in each group. (C) MFE in each group.

We performed serial flow cytometry to explore the relationship between $\mathrm{CD} 44^{+} \mathrm{CD} 24^{-}$and $\mathrm{ALDH}^{+}$cell populations, corresponding to the expression of markers that are widely used to characterize BCSCs. Overall, ALDH1 ${ }^{+}$BCSCs were highly enriched in the CM-CAFs group (Fig. $4 \mathrm{~A}-\mathrm{C}$ ), whereas cells in the CM-NFs group were enriched for the $\mathrm{CD} 44^{+} \mathrm{CD} 24-$ population (Fig. $4 \mathrm{D}-\mathrm{F})$. Based on the ALDEFLUOR assay, the proportion of ALDH1 ${ }^{+}$cells increased in CM-CAFs relative to those in the groups with both DMEM/F12-control medium and NF-conditioned medium $(\mathrm{P}<0.01)$.

However, there was no significant difference in the proportion of the $\mathrm{CD} 44^{+} \mathrm{CD} 24^{-}$population between cells cultured CM-CAFs and cells cultured on DMEM/F12-control medium $(\mathrm{P}=0.181)$, but the proportion of $\mathrm{CD}_{4} 4^{+} \mathrm{CD} 24-\mathrm{BCSCs}$ was markedly increased among the cells cultured in CM-NFs $(\mathrm{P}<0.05)$.

Figure 4 CM from CAFs and NFs can induce phenotypic transition in BCSCs. (A-C) ALDH1 expression in MCF-7 mammospheres from the three groups based on the ALDEFLUOR assay followed by fluorescence activated cell-sorting (FACS). (D-F) CD24 and CD44 expression in 
332

333

MCF-7 mammospheres from the three groups as detected by FACS. (G-H) Localization of CD44 (green), ALDH1 (red) and DAPI (blue) in mammospheres adhered to glass slides as assessed by immunofluorescence. Bar: $100 \mu \mathrm{m}$.

Further, the expression of CD44 and ALDH1 was examined using immunofluorescence in the two groups of mammospheres cultured in different CM. The expression of ALDH1 in the cytoplasm was enhanced by paracrine stimulation via CM-CAFs (Fig. 4G). Additionally, the mammospheres displayed significantly enhanced CD44 expression when cultured in CM-NFs (Fig. 4H).

\section{Discussion}

In the present study, we used proteomics methods to investigate the protein profiling of breast cancer CAFs and their normal counterpart NFs, which were isolated from breast cancer and paired with paracancerous tissues. We found that the differences in expression patterns between CAFs and NFs were mainly focused on the regulation of cellular extracellular matrix remodelling, metabolism and regulation of TGF- $\beta$ pathways. We also found that the CM from CAFs and NFs has different biological functions in promoting the invasiveness of breast cancer cells, consistent with previous reports (Chen et al. 2012). Interestingly, our work demonstrated that the CM from both CAFs and NFs could increase the MFE of MCF-7 cells. Compared with the CM from CAFs, the $\mathrm{CM}$ from NFs could induce an increase in the proportion of CD44 ${ }^{+} \mathrm{CD} 24-\mathrm{BCSC}$. Considering that the evidence-based data, which illustrates the effect of fibroblasts on the phenotypic transformation of BCSCs to various states, are limited and tend to rely on studies focusing on CAFs (Gunaydin et al. 2013; Lisanti et al. 2014), the present study might broaden our horizons of the critical roles of both CAFs and NFs in the dedifferentiation and phenotype conversion of breast cancer cells.

Though several studies have already reported several classic biomarkers for CAFs, few of them are proved to be specific, such as $\alpha$-SMA (Qiao et al. 2016). In this study, immunohistochemical (IHC) staining was applied to detect the expression levels of $\alpha$-SMA in paraffin-embedded breast cancer tissues and para-carcinoma tissues and in isolated CAFs/NFs, and we found that both CAFs and NFs expressed $\alpha$-SMA, as observed in previous studies (Huang, Li et al. 2010), despite some differences in staining patterns. This finding drives us to conduct a systemic evaluation of protein expression between CAFs and NFs. Heat map cluster analysis demonstrated the differences between the protein expression profiles of these two fibroblast types, which were consistent with 
previously reported GeneChip data (Al-Rakan et al. 2013; Pasanen et al. 2016). Furthermore, GO analysis revealed that compared to the proteins up-regulated in NFs, the proteins up-regulated in CAFs were associated with cytoskeleton formation, cell adhesion and integrin-mediated signalling pathways. Moreover, the identified proteins regulate the TGF- $\beta$ signal pathway. However, the proteins down-regulated in CAFs were associated with gene transcription and translation, lysosome transport, oxidative stress, mitochondria and cell morphology, among other processes. KEGG analysis showed that the pathways up-regulated in CAFs were associated with intercellular adhesion and connection. These pathways can also regulate the formation of the cytoskeleton. The pathways down-regulated in CAFs were associated with RNA degradation, RNA transport and fatty acid metabolism. Our data provide a comprehensive view of the protein profiling of CAFs and NFs, which might provide valuable biomarkers for CAFs. In fact, data mining and validation to identify intracellular and secreted extracellular protein expression profiles in CAFs and NFs are ongoing.

There is a consensus that CAFs can affect the invasive behaviour of breast cancer cells (Luo et al. 2015). However, the underlying mechanism of how CAFs affect the invasive potential of breast cancers is still uncertain. In the present study, we proved that the CM from CAFs could promote the invasiveness of the breast cancer cell line MCF-7, which could be explained by our proteomic results that the well-known TGF- $\beta$ oncogenic signalling pathway was significantly up-regulated in CAFs. We hypothesized that CAFs could enhance the metastatic potential of breast cancer cells though the paracrine stimulation of TGF- $\beta$. In fact, there have been reports of TGF- $\beta$ supported tumour invasion by several mechanisms, for example, stimulating the trans-differentiation of epithelial cancer cells into migratory mesenchymal cells, namely the epithelial-mesenchymal transition (EMT) process ( $\mathrm{Yu}$ et al. 2014). In addition, in some human breast cancer cells, organization of the invadopodia or degradation of the ECM requires extracellular or intracellular signal-regulated kinase signalling through phosphatidylinositide 3-kinase and Src kinase, which is also governed by TGF- $\beta$ (Mandal et al. 2008; Pignatelli et al. 2012). In our subsequent work, we will investigate whether TGF- $\beta$ signalling contributes to CAF-induced acquisition of invasion potential in breast cancer cells. Moreover, details of the mechanism will be illustrated.

The highlight in our study is that we clarified the roles of CAFs and NFs in the induction of cancer stem cells. Compared with the DMEM/F12-control medium, the CM from CAFs and NFs could significantly enhance the MFE of MCF-7 cells. Among the CM from the two kinds of fibroblasts, the mammosphere-promoting effect was stronger for the CM-CAFs. These data are also consistent 
with the findings of stem cell-related studies in which fibroblasts are used as feeder cells or in coculture systems cells to maintain the characteristics of stem cells and to induce the dedifferentiation of non-stem cells (Chen et al. 2014; Zhang et al. 2011). Further, using flow cytometry and immunofluorescence, we found that the cytokines or exosomes secreted by CAFs and NFs could induce the phenotypic transformation of BCSCs. ALDH1, CD44 and CD24 are common markers used for the identification of BCSCs. Previous studies on the effects of tumour stroma on BCSCs did not investigate the effect on phenotypic transformation. Liu et al. proposed that although $\mathrm{ALDH}^{+}{ }^{+} \mathrm{BCSCs}$ and $\mathrm{CD} 44^{+} \mathrm{CD} 24-\mathrm{BCSC}$ are overlapping cell populations, they are not identical (Liu et al. 2014). The former cell population is highly proliferative, while a majority of $\mathrm{CD} 44^{+} \mathrm{CD} 24-\mathrm{BCSC}$ are typically quiescent. A rare proportion of $\mathrm{ALDH} 1^{+}$and $\mathrm{CD} 44^{+} \mathrm{CD} 24^{-}$ BCSCs displays very strong tumourigenicity in vivo (Croker et al. 2009). Immunofluorescence assay showed that $\mathrm{ALDH} 1^{+} \mathrm{BCSCs}$ and $\mathrm{CD} 44^{+} \mathrm{CD} 24^{-} \mathrm{BCSC}$ are localized in different regions within the tumour tissue. The former cell population is typically located in the centre of the tumour, while the latter is located more at the periphery. In this study, the proportion of $\mathrm{ALDH} 1^{+} \mathrm{BCSCs}$ was relatively increased in response to CM-CAFs; however, BCSCs treated with CM-NFs were more likely to undergo phenotypic transformation into $\mathrm{CD} 44^{+}$populations. Thus, we hypothesized that the effect of fibroblasts on BCSCs may be multidirectional. Fibroblasts at different states may have different effects on BCSC populations and thus promote diverse biological processes. As shown in this study, CM-CAFs could promote the invasion of tumour cells in a paracrine manner, while cytokines secreted by NFs suppressed local invasion of tumour cells. Since accumulating evidence has demonstrated a crucial role of TGF- $\beta$ in the regulation of cancer stem cell function (Watabe \& Miyazono 2009), it has been observed that TGF- $\beta$ can affect the generation and outcome of normal and malignant stem cells through various mechanisms (Watabe \& Miyazono 2009). In breast cancer, previous studies have reported that the activation of the TGF- $\beta$ pathway can enrich CD44 $4^{+}$BCSCs (Shipitsin et al., 2007). However, other groups have also found that active TGF- $\beta$ signalling can increase a subpopulation of stemness cells that express ALDH1 (Zheng R 2014), suggesting that the regulatory function of TGF- $\beta$ in BCSCs is complicated. In our present work, we found that TGF- $\beta$ activated fibroblasts, namely the CAFs, could increase the proportion of ALDH $1^{+}$BCSCs via their conditioned medium. These results hinted that TGF- $\beta$ as a paracrine factor might be effective as a regulator in the transformation of BCSC subpopulations from $\mathrm{CD}_{4} 4^{+}$to $\mathrm{ALDH} 1^{+}$. This study expanded on the conclusion that fibroblasts can promote the generation of cancer stem cells. Further, we will study whether such a subpopulation conversion is associated with tumour progression, such as tumour invasion, and the underlying mechanism of this process. 
434 This study has some potential limitations. First, although in vivo experiments are the gold standard for verifying the self-renewal ability of cancer stem cells, we cannot prevent phenotypic changes induced by tumour cells in NFs in vivo. We do not have data from in vivo experiments investigating the effects of NFs and CAFs on cancer stem cells. In addition, this research only proves that $\mathrm{CM}$ from CAFs or NFs enrich the BCSCs, however future study is needed to find out the exact approach that induces this promoting effect. It may the result of increased proliferation of BCSCs, represent of low apoptosis ration, or the conversion of non-stem cells into stem cells. At last, because this study is preliminary, the results merely describe the effect of CAFs/NFs on the phenotype of BCSCs from a functional perspective. Further molecular analyses are needed to explore the associated cytokines or pathways, and we will pursue this direction in the future.

\section{Conclusions}

In summary, our preliminary study validated the existence of heterogeneity among CAFs and NFs from a proteomics perspective. Both types of fibroblasts promoted the self-renewal capacity of BCSCs and induced the phenotypic transformation of non-stem cells to cancer stem cells. However, during this process, CAFs and NFs showed different extents of promotive ability and different directions of phenotypic transformation in BCSCs. Further investigation on the effect of NFs on cancer stem cells may provide a new direction for the elucidation of the initial stages of tumour metastasis. Additionally, insights into the effects of CAFs/NFs on BCSCs may provide new directions in the study of breast cancer treatment. Based on the functional evidence obtained in this study, further studies will be carried out to explore the molecular mechanisms and relative pathways involved in the phenotypic transformation of BCSCs.

\section{Acknowledgements}

We thank Prof Jun Qin, Ph.D., State Key Laboratory of Proteomics, National Center for Protein Sciences, Beijing Proteome Research Center, Yeqing Cui, medical laboratory technician of Xuanwu Hospital Surgery Lab, Jiaying Yu, Ph.D., Institute of Biophysics, Chinese Academy of Sciences, for their expertise and help during this project, and Dr Tian Lan, Dr Ye Cheng and Dr Fei Gao for proofreading and language check.

\section{References}


A DACP, and Lopes C. 2017. Implications of Different Cancer Stem Cell Phenotypes in Breast Cancer. Anticancer Res 37:2173-2183. 10.21873/anticanres.11552

Al-Hajj M, Wicha MS, Benito-Hernandez A, Morrison SJ, and Clarke MF. 2003. Prospective identification of tumorigenic breast cancer cells. Proc Natl Acad Sci US A 100:3983-3988. 10.1073/pnas.0530291100

Al-Rakan MA, Colak D, Hendrayani SF, Al-Bakheet A, Al-Mohanna FH, Kaya N, Al-Malik O, and Aboussekhra A. 2013. Breast stromal fibroblasts from histologically normal surgical margins are pro-carcinogenic. J Pathol 231:457-465. 10.1002/path.4256

Bernardi MA, Logullo AF, Pasini FS, Nonogaki S, Blumke C, Soares FA, and Brentani MM. 2012. Prognostic significance of CD24 and claudin-7 immunoexpression in ductal invasive breast cancer. Oncol Rep 27:2838. 10.3892/or.2011.1477

Boesch M, Sopper S, Zeimet AG, Reimer D, Gastl G, Ludewig B, and Wolf D. 2016. Heterogeneity of Cancer Stem Cells: Rationale for Targeting the Stem Cell Niche. Biochim Biophys Acta 1866:276-289. 10.1016/j.bbcan.2016.10.003

Buchsbaum RJ, and Oh SY. 2016. Breast Cancer-Associated Fibroblasts: Where We Are and Where We Need to Go. Cancers (Basel) 8. 10.3390/cancers8020019

Bussard KM, Mutkus L, Stumpf K, Gomez-Manzano C, and Marini FC. 2016. Tumor-associated stromal cells as key contributors to the tumor microenvironment. Breast Cancer Res 18:84. 10.1186/s13058-016-0740-2

Chen P, Mo Q, Wang B, Weng D, Wu P, and Chen G. 2012. Breast cancer associated fibroblasts promote MCF-7 invasion in vitro by secretion of HGF. J Huazhong Univ Sci Technolog Med Sci 32:92-96. 10.1007/s11596012-0016-8

Chen WJ, Ho CC, Chang YL, Chen HY, Lin CA, Ling TY, Yu SL, Yuan SS, Chen YJ, Lin CY, Pan SH, Chou HY, Chen YJ, Chang GC, Chu WC, Lee YM, Lee JY, Lee PJ, Li KC, Chen HW, and Yang PC. 2014. Cancerassociated fibroblasts regulate the plasticity of lung cancer stemness via paracrine signalling. Nat Commun 5:3472. 10.1038/ncomms4472

Chiotaki R, Polioudaki H, and Theodoropoulos PA. 2016. Stem cell technology in breast cancer: current status and potential applications. Stem Cells Cloning 9:17-29. 10.2147/SCCAA.S72836

Croker AK, Goodale D, Chu J, Postenka C, Hedley BD, Hess DA, and Allan AL. 2009. High aldehyde dehydrogenase and expression of cancer stem cell markers selects for breast cancer cells with enhanced malignant and metastatic ability. J Cell Mol Med 13:2236-2252. 10.1111/j.1582-4934.2008.00455.x

Darby IA, Zakuan N, Billet F, and Desmouliere A. 2016. The myofibroblast, a key cell in normal and pathological tissue repair. Cell Mol Life Sci 73:1145-1157. 10.1007/s00018-015-2110-0

Erdogan B, and Webb DJ. 2017. Cancer-associated fibroblasts modulate growth factor signaling and extracellular matrix remodeling to regulate tumor metastasis. Biochem Soc Trans 45:229-236. 10.1042/BST20160387

Giannoni E, Bianchini F, Masieri L, Serni S, Torre E, Calorini L, and Chiarugi P. 2010. Reciprocal activation of prostate cancer cells and cancer-associated fibroblasts stimulates epithelial-mesenchymal transition and cancer stemness. Cancer Res 70:6945-6956. 10.1158/0008-5472.CAN-10-0785 
501

502

503

504

505

506

507

508

509

510

511

512

Ginestier C, Hur MH, Charafe-Jauffret E, Monville F, Dutcher J, Brown M, Jacquemier J, Viens P, Kleer CG, Liu S, Schott A, Hayes D, Birnbaum D, Wicha MS, and Dontu G. 2007. ALDH1 is a marker of normal and malignant human mammary stem cells and a predictor of poor clinical outcome. Cell Stem Cell 1:555-567. 10.1016/j.stem.2007.08.014

Gunaydin G, Dolen Y, and Kesikli SA. 2013. Fibroblast-derived CCL2 induces cancer stem cells--letter. Cancer Res 73:1031. 10.1158/0008-5472.CAN-12-2379

Li X, Lewis MT, Huang J, Gutierrez C, Osborne CK, Wu MF, Hilsenbeck SG, Pavlick A, Zhang X, Chamness GC, Wong H, Rosen J, and Chang JC. 2008. Intrinsic resistance of tumorigenic breast cancer cells to chemotherapy. J Natl Cancer Inst 100:672-679. 10.1093/jnci/djn123

Lisanti MP, Tsirigos A, Pavlides S, Reeves KJ, Peiris-Pages M, Chadwick AL, Sanchez-Alvarez R, Lamb R, Howell A, Martinez-Outschoorn UE, and Sotgia F. 2014. JNK1 stress signaling is hyper-activated in high breast density and the tumor stroma: connecting fibrosis, inflammation, and stemness for cancer prevention. Cell Cycle 13:580-599. 10.4161/cc.27379

Liu S, Cong Y, Wang D, Sun Y, Deng L, Liu Y, Martin-Trevino R, Shang L, McDermott SP, Landis MD, Hong S, Adams A, D'Angelo R, Ginestier C, Charafe-Jauffret E, Clouthier SG, Birnbaum D, Wong ST, Zhan M, Chang JC, and Wicha MS. 2014. Breast cancer stem cells transition between epithelial and mesenchymal states reflective of their normal counterparts. Stem Cell Reports 2:78-91. 10.1016/j.stemcr.2013.11.009

Luo H, Tu G, Liu Z, and Liu M. 2015. Cancer-associated fibroblasts: a multifaceted driver of breast cancer progression. Cancer Lett 361:155-163. 10.1016/j.canlet.2015.02.018

Mandal S, Johnson KR, and Wheelock MJ. 2008. TGF-beta induces formation of F-actin cores and matrix degradation in human breast cancer cells via distinct signaling pathways. Exp Cell Res 314:3478-3493. 10.1016/j.yexcr.2008.09.013

Mansour SF, and Atwa MM. 2015. Clinicopathological Significance of CD133 and ALDH1 Cancer Stem Cell Marker Expression in Invasive Ductal Breast Carcinoma. Asian Pacific Journal of Cancer Prevention 16:7491-7496. 10.7314/apjcp.2015.16.17.7491

Pasanen I, Lehtonen S, Sormunen R, Skarp S, Lehtilahti E, Pietila M, Sequeiros RB, Lehenkari P, and Kuvaja P. 2016. Breast cancer carcinoma-associated fibroblasts differ from breast fibroblasts in immunological and extracellular matrix regulating pathways. Exp Cell Res 344:53-66. 10.1016/j.yexcr.2016.04.016

Pignatelli J, Tumbarello DA, Schmidt RP, and Turner CE. 2012. Hic-5 promotes invadopodia formation and invasion during TGF-beta-induced epithelial-mesenchymal transition. J Cell Biol 197:421-437. $10.1083 / \mathrm{jcb} .201108143$

Plaks V, Kong N, and Werb Z. 2015. The cancer stem cell niche: how essential is the niche in regulating stemness of tumor cells? Cell Stem Cell 16:225-238. 10.1016/j.stem.2015.02.015

Qiao A, Gu F, Guo X, Zhang X, and Fu L. 2016. Breast cancer-associated fibroblasts: their roles in tumor initiation, progression and clinical applications. Front Med 10:33-40. 10.1007/s11684-016-0431-5 
536

537

538

539

540

541

542

543

544

545

546

547

548

549

550

551

552

553

554

Shaw FL, Harrison H, Spence K, Ablett MP, Simoes BM, Farnie G, and Clarke RB. 2012. A detailed mammosphere assay protocol for the quantification of breast stem cell activity. J Mammary Gland Biol Neoplasia 17:111117. 10.1007/s10911-012-9255-3

Somasundaram V, Hemalatha SK, Pal K, Sinha S, Nair AS, Mukhopadhyay D, and Srinivas P. 2016. Selective mode of action of plumbagin through BRCA1 deficient breast cancer stem cells. BMC Cancer 16:336. 10.1186/s12885-016-2372-4

Watabe T, and Miyazono K. 2009. Roles of TGF-beta family signaling in stem cell renewal and differentiation. Cell Res 19:103-115. 10.1038/cr.2008.323

Yang F, Xu J, Tang L, and Guan X. 2017. Breast cancer stem cell: the roles and therapeutic implications. Cell Mol Life Sci 74:951-966. 10.1007/s00018-016-2334-7

Yu Y, Xiao CH, Tan LD, Wang QS, Li XQ, and Feng YM. 2014. Cancer-associated fibroblasts induce epithelialmesenchymal transition of breast cancer cells through paracrine TGF-beta signalling. Br J Cancer 110:724732. 10.1038/bjc.2013.768

Zhang F, Song C, Ma Y, Tang L, Xu Y, and Wang H. 2011. Effect of fibroblasts on breast cancer cell mammosphere formation and regulation of stem cell-related gene expression. Int J Mol Med 28:365-371. 10.3892/ijmm.2011.700

Zheng R WJ, Wu Q, Wang Z, Ou Y, Ma L, Wang M, Wang J, Yang Y. 2014. Expression of ALDH1 and TGFß2 in benign and malignant breast tumors and their prognostic implications. Int J Clin Exp Pathol 7:4173-4183. 


\section{Table $\mathbf{1}$ (on next page)}

Clinical information of the specimen donors.

Age represents the age of the donor at the time of surgery. The histological type of the tissue was invasive ductal carcinoma (IDC). Oestrogen and progesterone receptor status is indicated as "positive/negative" with the corresponding percentage of positive cells. HER-2 positivity in the tissues was determined by fluorescence in situ hybridization (FISH). 


\begin{tabular}{|c|c|c|c|c|c|c|c|c|c|}
\hline $\begin{array}{l}\text { Sample } \\
\text { name }\end{array}$ & $\begin{array}{l}\text { Patient' } \\
\text { age }\end{array}$ & $\begin{array}{l}\text { Histological } \\
\text { type }\end{array}$ & $\begin{array}{l}\text { Largest } \\
\text { diameter }\end{array}$ & ER & PR & HER-2 & Ki67 & $\begin{array}{l}\text { Axillary } \\
\text { lymph node } \\
\text { metastasis }\end{array}$ & Cyclomastopathy \\
\hline $\begin{array}{c}\text { CAF-g/ } \\
\text { NF-g }\end{array}$ & 46 & IDC & $25 \mathrm{~mm}$ & $\begin{array}{l}+, \\
80 \\
\%\end{array}$ & $\begin{array}{l}+, \\
40 \%\end{array}$ & Negative & $15 \%$ & Yes & Yes \\
\hline $\begin{array}{l}\text { CAF-h/ } \\
\text { NF-h }\end{array}$ & 33 & IDC & $33 \mathrm{~mm}$ & $\begin{array}{l}+, \\
95 \\
\%\end{array}$ & $\begin{array}{l}+, \\
10 \%\end{array}$ & Negative & $20 \%$ & Yes & Yes \\
\hline $\begin{array}{l}\text { CAF-i/ } \\
\text { NF-i }\end{array}$ & 60 & IDC & $18 \mathrm{~mm}$ & $\begin{array}{l}+, \\
95 \\
\%\end{array}$ & $\begin{array}{l}+, \\
80 \%\end{array}$ & Positive & $5 \%$ & No & Yes \\
\hline $\begin{array}{l}\text { CAF- } \\
\text { I/NF-I }\end{array}$ & 44 & IDC & $26 \mathrm{~mm}$ & $\begin{array}{l}+, \\
80 \\
\%\end{array}$ & - & Negative & $25 \%$ & Yes & Yes \\
\hline $\begin{array}{l}\text { CAF- } \\
\text { m/NF- } \\
\text { m }\end{array}$ & 47 & IDC & $30 \mathrm{~mm}$ & $\begin{array}{l}+, \\
95 \\
\%\end{array}$ & $\begin{array}{l}+, \\
90 \%\end{array}$ & Negative & $15 \%$ & Yes & Yes \\
\hline $\begin{array}{l}\text { CAF- } \\
\text { n/NF-n }\end{array}$ & 66 & IDC & $30 \mathrm{~mm}$ & $\begin{array}{l}+, \\
95 \\
\%\end{array}$ & - & Negative & $30 \%$ & Yes & Yes \\
\hline
\end{tabular}

Table 1 Clinical information of the specimen donors. Age represents the age of the donor at the time of surgery. The histological type of the tissue was invasive ductal carcinoma (IDC). Oestrogen and progesterone receptor status is indicated as "positive/negative" with the corresponding percentage of positive cells. HER-2 positivity in the tissues was determined by fluorescence in situ hybridization (FISH). 


\section{Figure 1}

Cell morphology and $\alpha$-SMA expression cannot be used to distinguish CAFs and NFs, but these fibroblasts differ in their biological functions.

(A-B) CAFs and NFs are both morphologically characterized as large spindle-shaped cells with indented nuclei. Bar: $100 \mu \mathrm{m}$. (C-D) Immunohistochemical staining for $\alpha$-SMA in CAFs and NFs. Both samples are positive for $\alpha$-SMA expression. Bar: $100 \mu \mathrm{m}$. (E-F) Immunohistochemical staining for $\alpha$-SMA in a cancer tissue and a paracancerous tissue more than $3 \mathrm{~cm}$ away from carcinoma. Bar: $100 \mu \mathrm{m}$. (G-I) Invasion of MCF-7 cells was affected by CM. Bar: $100 \mu \mathrm{m}$. 
A

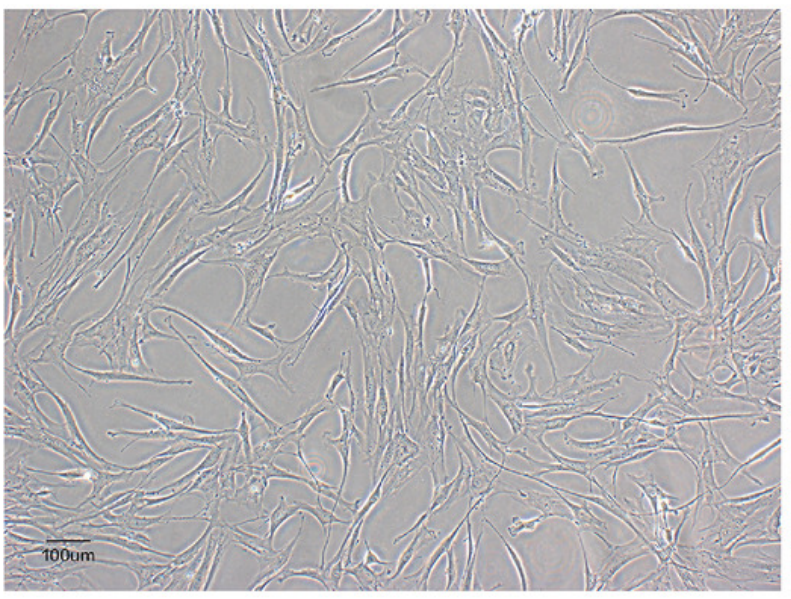

\section{C}

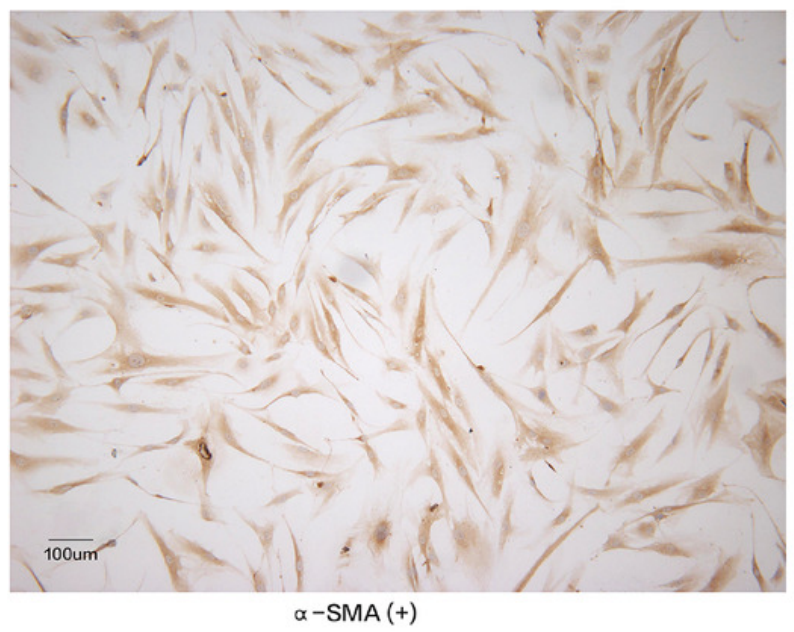

E

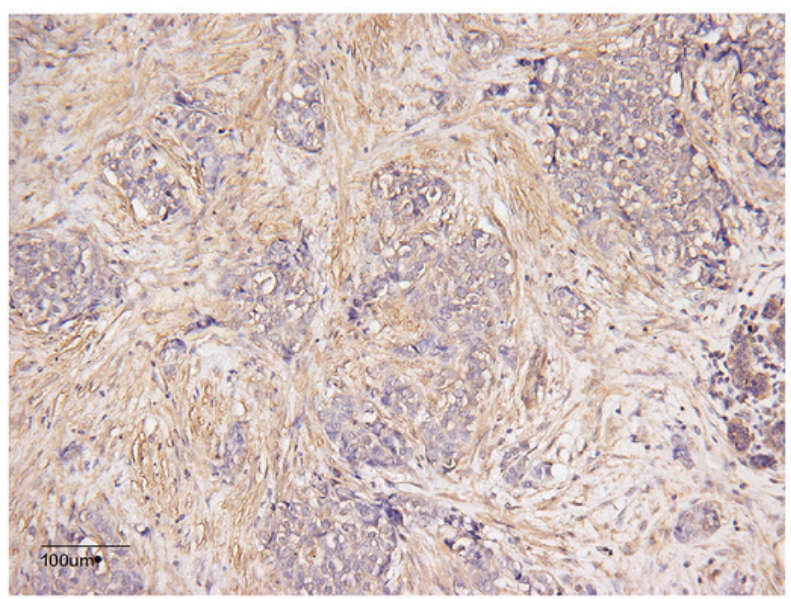

B

NFs

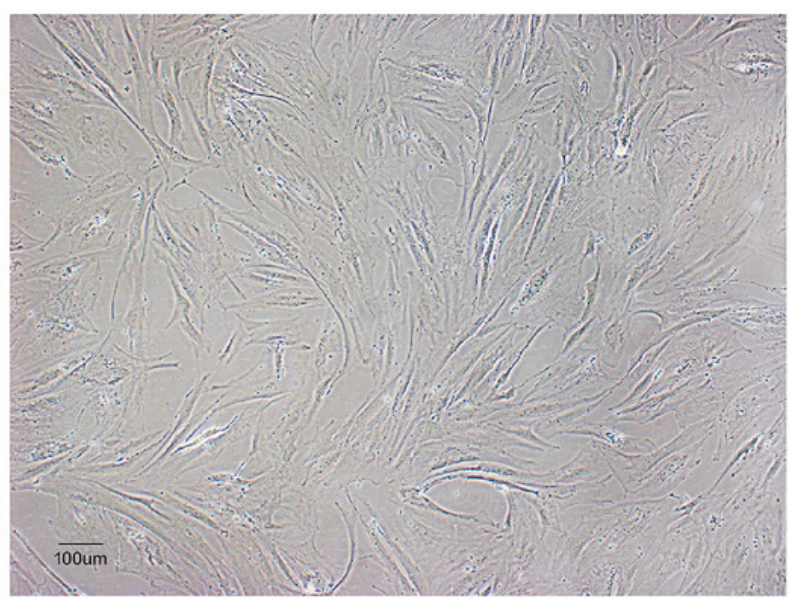

D

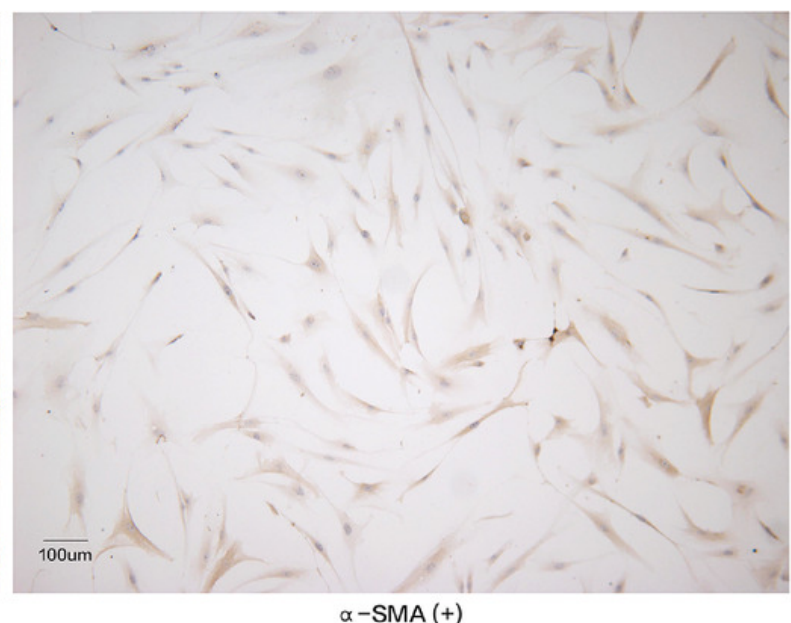

F

Paracancer tissue
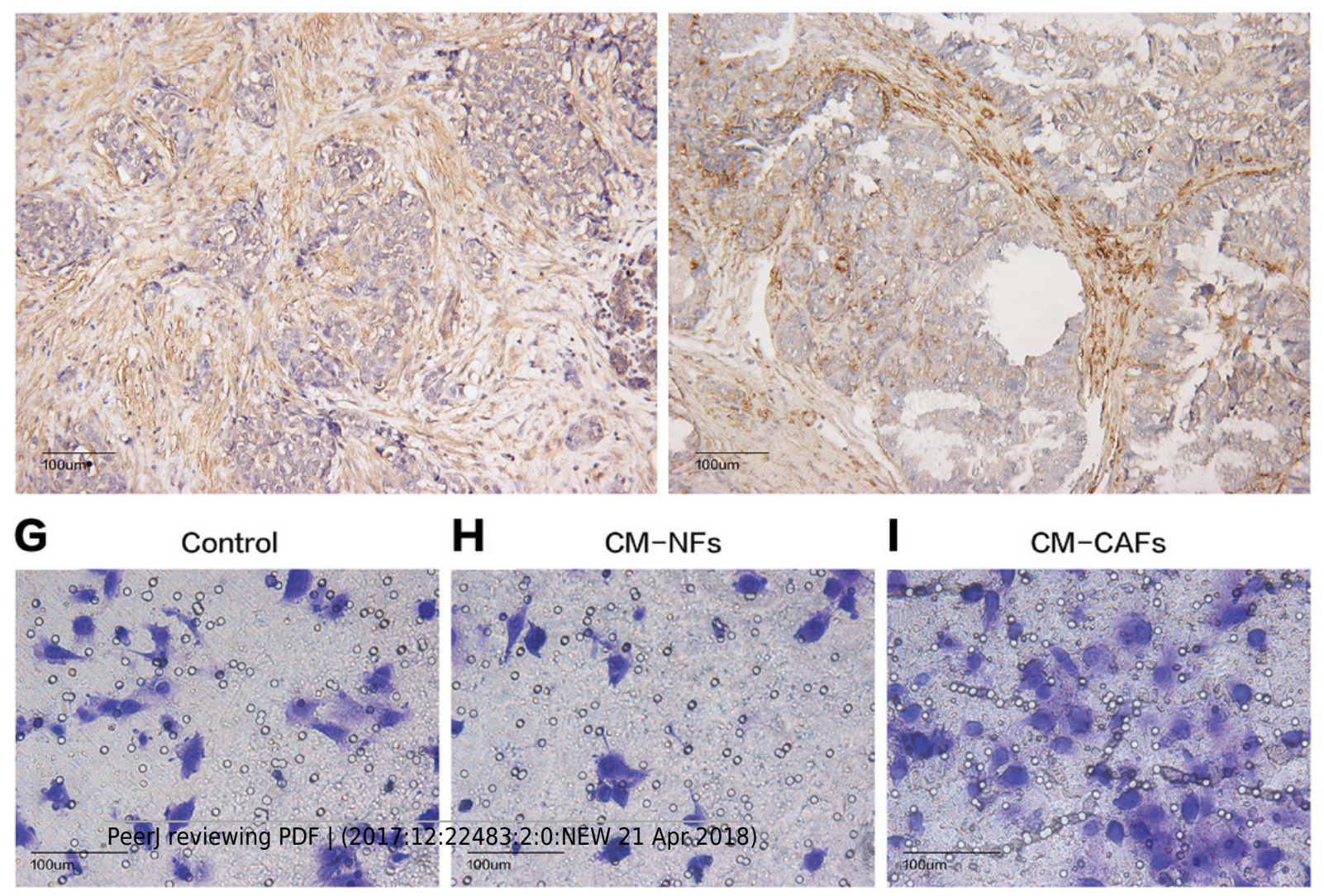


\section{Figure 2}

CAFs and NFs are heterogeneous in terms of their protein expression profiles, cellular functions and related signalling pathways.

(A) Heterogeneity in the expression of selected proteins (fold-change $<-2$ or $>2, P<0.05$ ) between CAFs and NFs. Blue represents down-regulated expression, and red indicates upregulated expression. All data are transformed by log2 operation. (B) Gene ontology (GO)based enrichment analysis of up-regulated proteins in CAFs (orange bars) and in paired NFs (blue bars), including cell component (CC), biological process (BP) and molecular function (MF). (C) KEGG pathway analysis for identifying major biological pathways that were different between CAFs (orange bars) and NFs (blue bars). 


\section{A}

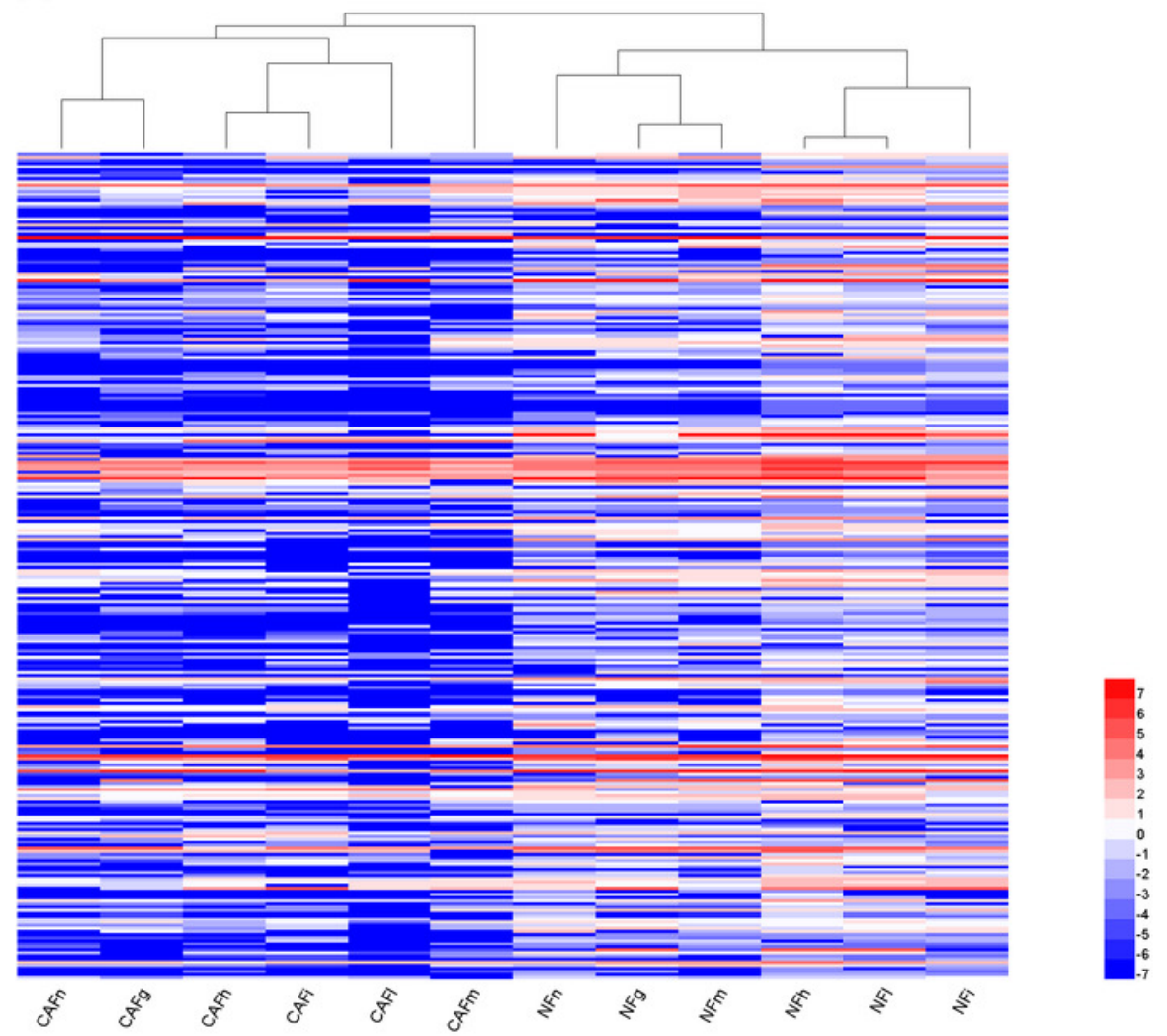

\section{B}

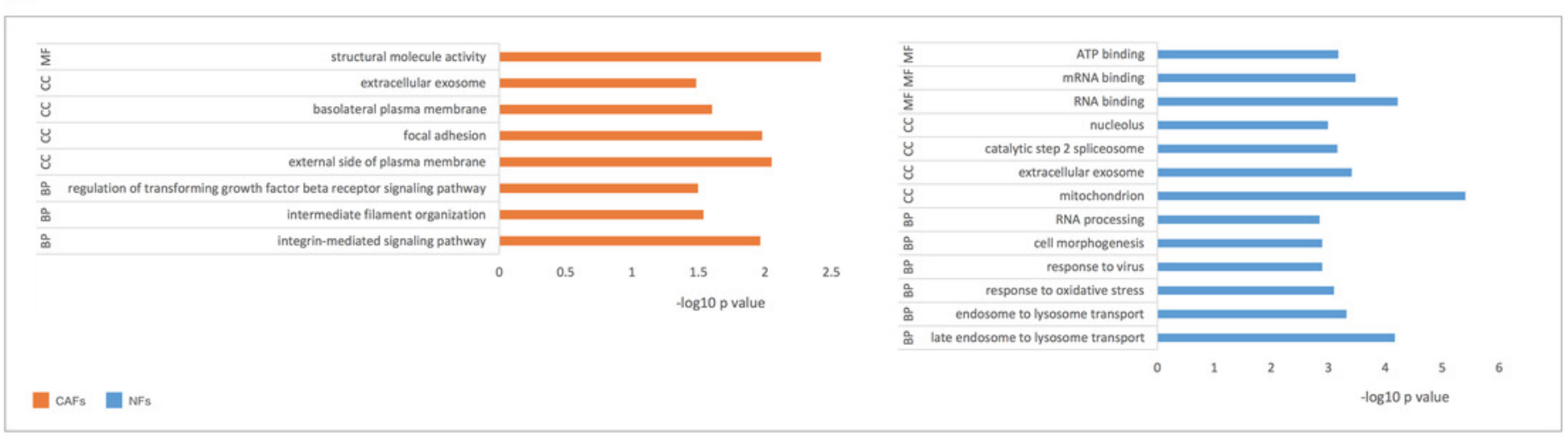

\section{C}

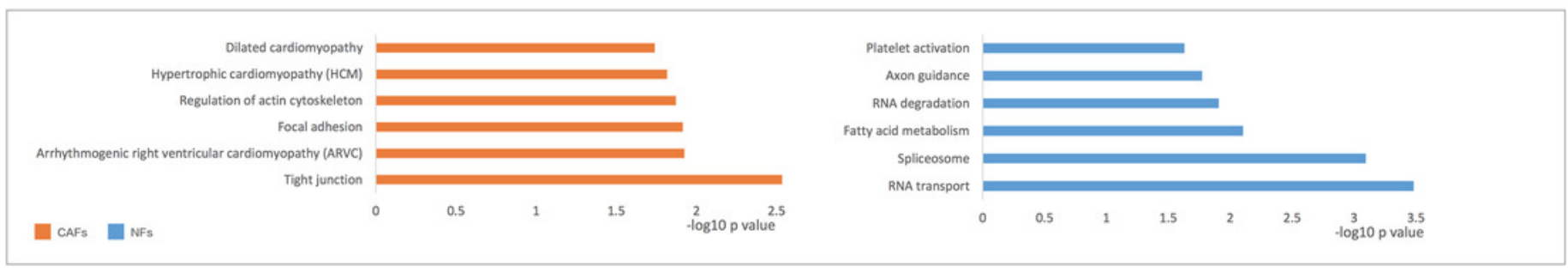


Figure 3

Mammosphere formation by MCF-7 cells cultured in CM.

(A) Mammosphere formation in MCF-7 cells in the control, CM-NFs (cultured in CM-NFs) and CM-CAFs (cultured in CM-CAFs) groups. Bar: $100 \mu \mathrm{m}$. (B) Number of mammospheres greater than $50 \mu \mathrm{m}$ in diameter in each group. (C) MFE in each group.

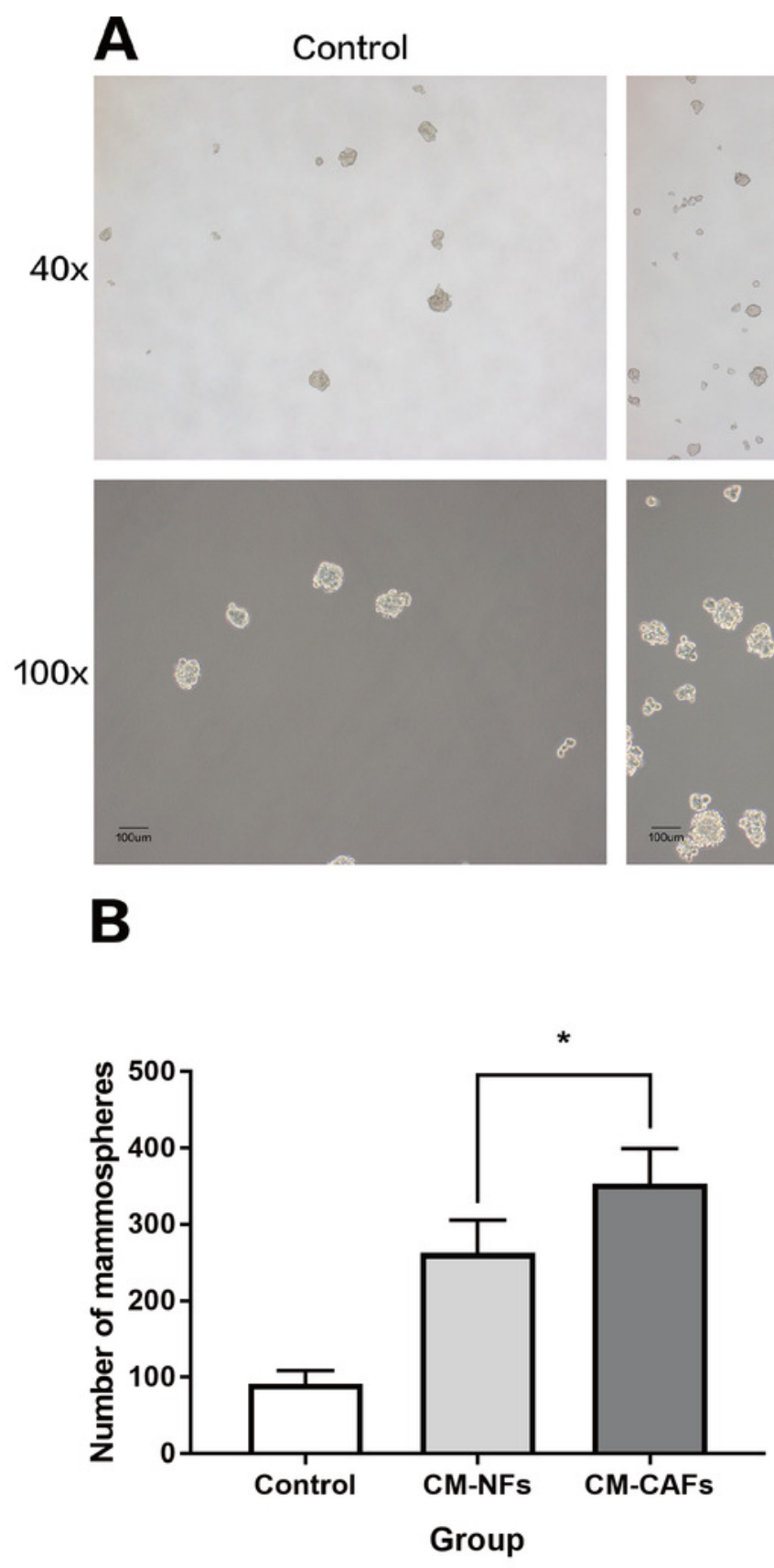

CM-NFs

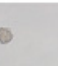

10

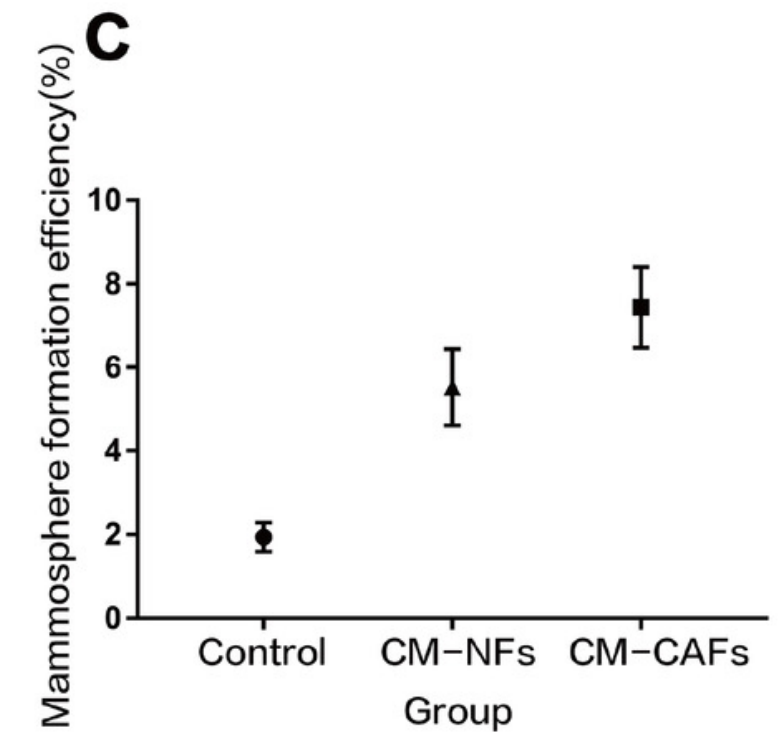




\section{Figure 4}

CM from CAFs and NFs can induce phenotypic transition in BCSCs.

(A-C) ALDH1 expression in MCF-7 mammospheres from the three groups based on the ALDEFLUOR assay followed by fluorescence activated cell-sorting (FACS). (D-F) CD24 and CD44 expression in MCF-7 mammospheres from the three groups as detected by FACS. (G-H) Localization of CD44 (green), ALDH1 (red) and DAPI (blue) in mammospheres adhered to glass slides as assessed by immunofluorescence. Bar: $100 \mu \mathrm{m}$. 

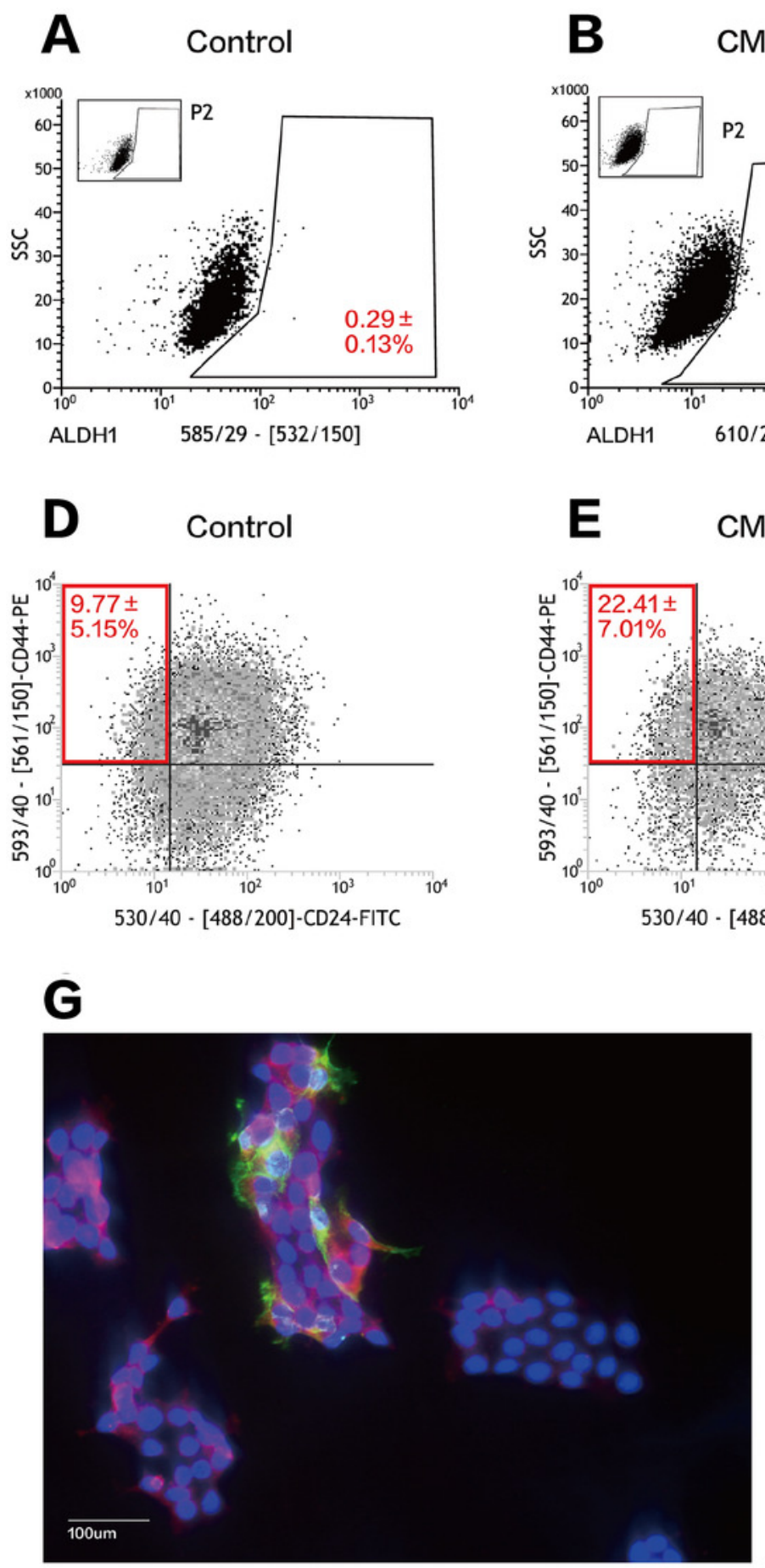

CM-CAFs
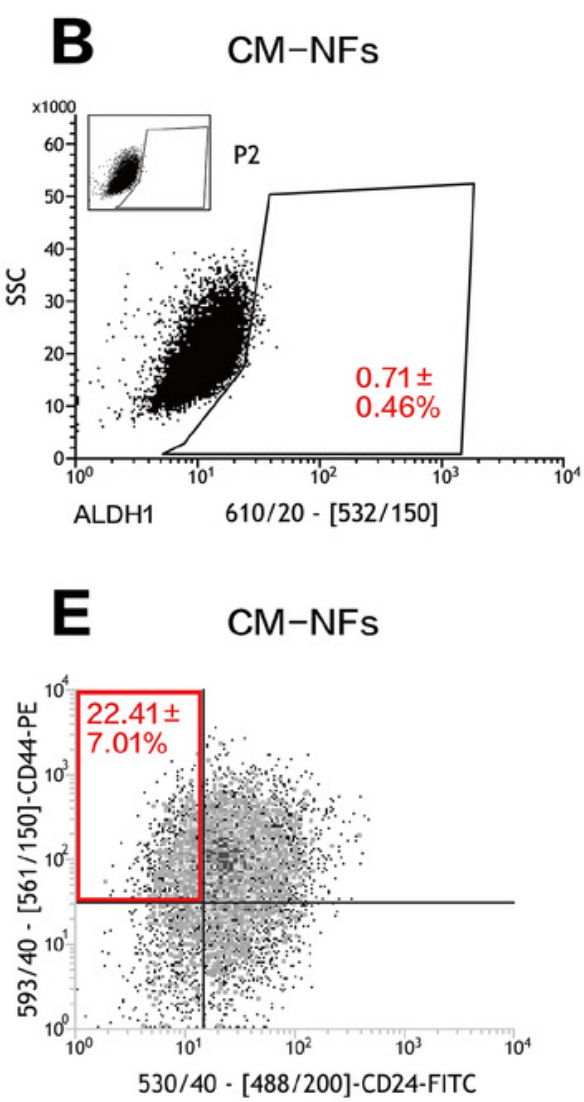

H

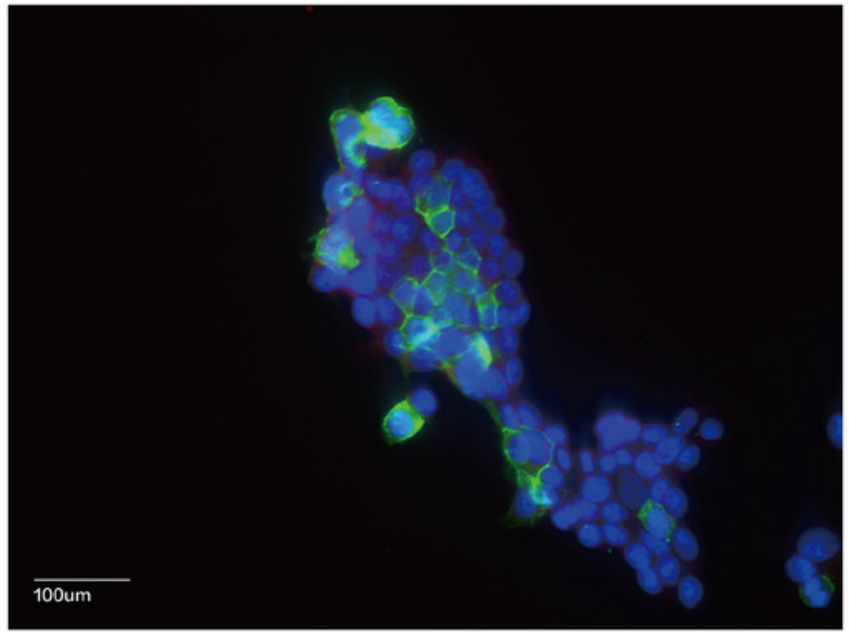

CM-NFs 